\title{
Görme Engelliler için Vücudun Okuma Hassasiyetinin Ölçülmesi*
}

\author{
İlknur Avşar ${ }^{1}$, Murat Furat ${ }^{2}$ \\ 1 İskenderun Teknik Üniversitesi, Mühendislik ve Doğa Bilimleri Fakültesi, Elektrik ve Elektronik Mühendisliği, Hatay, Türkiye (ORCID: 0000-0001-8987-2136) \\ 2 İskenderun Teknik Üniversitesi, Mühendislik ve Doğa Bilimleri Fakültesi, Elektrik ve Elektronik Mühendisliği, Hatay, Türkiye (ORCID: 0000-0003-3179-5099)
}

(Konferans Tarihi: 5-7 Mart 2020)

(DOI: $10.31590 /$ ejosat.araconf44)

\begin{abstract}
ATIF/REFERENCE: Avşar, İ., \& Furat, M. (2020). Görme Engelliler için Vücudun Okuma Hassasiyetinin Ölçülmesi. Avrupa Bilim ve Teknoloji Dergisi, (Özel Say1), 342-348.
\end{abstract}

\section{$\ddot{O} z$}

Bilindiği gibi görme engelliler ve diğer engelli bireylerin sosyal hayata entegrasyonu yönünde birçok çalışma yapılmakta fakat yapılan çalışmaların birçoğu engelli bireylerin hareket, konfor gibi durumlarını sınırlamaktadır. Özellikle hareket kabiliyeti düşük olan görme engelli bireylerde hareket kabiliyetlerini kısıtlamayacak cihazlar geliştirilmesi ihtiyacı bulunmaktadır. Görme engelli bireylerin sosyal yaşamdaki karşılaştığı sorunları ele alındığında, birçok alanda ciddi gelişmelerin yaşandığı günümüz şartlarında, görme engelli kişilerin yeteri kadar teknolojiden faydalanmayıp, okuma yetenekleri sadece Braille alfabesi ile yazılan metinler ve sayısal ortamdaki metinleri sese çevirebilen teknolojilerden ibarettir. Her iki durumda da mobilitelerinin kıstllı olması sebebiyle sosyal ortamdan uzak kalmaları büyük sorun teşkil etmektedir. Bunun yanı sıra, görme engelli bireylerin kullanacağı ve kültürel gelişimine katkıda bulunabilecek nitelikte materyallerin (kitap, dergi, gazete v.b) kısıtlı olması, üretilen materyallerin kullanılan alfabe tekniği nedeniyle ulaşılmasının zor olması veya maliyetinin yüksek olması sorun olmaktadır. Özellikle görme engelli bireylerin hareket kabiliyetlerini kısıtlamadan ve dış ortamdan izole olmadan dijital ortamdaki metinleri daha çok titreşim yoluyla okuma yapabilmesi için, vücutta kişinin çeşitli bölgeleri üzerinde bir çalışma yapılmış olup bu yolla yapacakları okuma hassasiyeti bu çalışmada araştırılmıştır.

Anahtar Kelimeler: Görme Engelli, Braille, Mobilite, Titreşim ile Okuma

\section{Reading Sensivity Measurement of the Body for the Visually Impaired}

\begin{abstract}
It is well known that many studies are carried out for the integration of visually impaired and other disabled individuals to social life, but many of the studies limit the conditions of disabled individuals such as movement and comfort. There is a need to develop devices that will not limit their mobility especially in individuals with low mobility. Considering the problems faced by visually impaired individuals in social life, in today's conditions where there are serious developments in many areas, visually impaired people do not benefit from enough technology, their reading skills are only the texts written in Braille alphabet and technologies that can translate texts in digital environment into sound. In both cases, because of their limited mobility, their being away from the social environment poses a big problem. In addition, it is a problem that the materials (books, magazines, newspapers, etc.) that are visually impaired and that can contribute to their cultural development are limited, the materials produced are difficult to access due to the alphabet technique used or the cost is high. In order to enable the visually impaired individuals to read the texts in the digital environment more by vibration without restricting their mobility and isolation from the external environment, a study was made on various parts of the body and their reading sensitivity was investigated in this study.
\end{abstract}

Keywords: Visually Impaired, Braille, Mobility, Reading with Vibration

${ }^{*}$ Bu makale International Conference on Access to Recent Advances in Engineering and Digitalization (ARACONF 2020) de sunulmuştur. 


\section{Giriş}

Görme engelli bireylerin sosyal yaşamdaki karşılaştı̆̆ sorunları ele alındığında, birçok alanda ciddi gelişmelerin yaşandığı günümüz şartlarında, görme engelli kişilerin yeteri kadar teknolojiden faydalanmayıp, mobilitelerinin kısıtlı olması sebebiyle sosyal ortamdan uzak kalmaları büyük sorun teşkil etmektedir. Bunun yanı sıra, görme engelli bireylerin kullanacağı ve kültürel gelişimine katkıda bulunabilecek nitelikte materyallerin (kitap, dergi, gazete v.b) kısıtlı olması, üretilen materyallerin kullanılan alfabe tekniği nedeniyle ulaşılmasının zor olması veya maliyetinin yüksek olması sorun olmaktadır. Bu konu ile ilgili olarak geçmişten günümüze kadar yapılan çalışmalara baktığımızda güncel teknolojilerin, engellilerin hayatını kolaylaştırmak amacıyla farklı yöntemlerle kullanıldığını görülmektedir [1].

Çalışmaya konu olan görme engelliler için geliştirilen yardımcı cihazların yapımında kullanılan malzemeler, amacına göre farklılık göstermektedir. Buna örnek olarak, görme engelli kişilerin önündeki engelleri tespit etmesini kolaylaştırmak amacıyla kamera veya çeşitli sensörler kullanılarak yapılan yardımcı cihazlar literatürde mevcuttur [2], [3], [4], [5], [6], [7], [8], [9], [10]. Bununla beraber, gideceği güzergahı GPS ile tespit edip engelli kişiyi yönlendiren sistemler de geliştirilmiştir [11] Kişilerin sosyal hayatları düşünüldüğünde temel ihtiyaçlarını karşılamak için gerekli yetenekleri sağlayacak renk tanıma, fiyat okuma, boyutu ve uzaklığını algılama gibi özellikleri olan cihazlar da gelişen teknolojiye paralel olarak yapılmaktadır [6], [7].

Görme engelli bireylerin okuma yapması için kullanılan en yaygın yöntem Braille alfabesidir. Braille alfabesi tekniği, 6 adet kabartma noktanın insan parmağının bir boğumunun içi gibi küçük bir alanda faklı kombinasyonlar ile harflerin temsiline dayanmaktadır. Kişi bu yolla okuma yapabilmek için düz bir zemin üzerinde Braille alfabe tekniği ile yazılmış metinleri parmak ucu hissiyatını kullanarak harfleri hisseder.

Şu anda teknolojinin gelişmesiyle ortaya çıkan diğer bir yöntem ise sayısal ortamdaki metinlerin robotik bir sesle okunmasıdır.

Her iki yönteminde görme engellilerin okumasında kolaylık sağlamasına rağmen önemli bazı sorunları da beraberinde getirmektedir.

Görme engelliler için yapılan çalışmalara bakıldığında, okuma eylemini gerçekleştiren görme engelli kişinin, harfleri algılayamaması, yanlış okuma yapması, his duygusunun körelmiş olması sebebi ile harfleri tanıyamaması gibi problemler sıklıkla yaşandığından, bu tür problemlere yönelik çeşitli çözümler literatürde mevcuttur [12]. Hissiyata dayalı Braille alfabesi ile okumaya alternatif yine hissiyata dayalı farklı bir teknik uygulanacaktır. Literatürde az sayıda bulunan görme engellilerin okumasına yönelik çalışmaların birçoğunda, kabartmaya dayalı harf sistemi sabit bir ekipman ile geliştirilmiştir [13], [14], [15].

Bilimsel gelişmelerden arkeolojik bulgulara, teknolojik faaliyetlerden güncel hayatta yaşanan olaylara kadar birçok alandaki haberlere engeli bulunmayan bireyler rahatlıkla ulaşabilirken, görme engelli bireylerin okuma yaptığı alfabenin farklı olması sebebi ile kendi kültürel gelişimine katkıda bulunabilecek çeşitli materyallere (kitap, dergi vb.) ulaşması oldukça zordur. Bu zorlukların başında Braille alfabesi ile hazırlanmış bu materyallerin çok az ve pahalı olması gelmektedir.

Görme engelli kişinin sosyal hayatta yaşanan gelişmeleri takibi amacıyla geliştirilen ses geri dönüşü olan cihazlar en kolay yöntem olarak bireylere sunulmuştur. Bu cihazların kullanımı bir kulaklık yardımı ile sağlanmaktadır. Bu cihazlar görme engelli bireylerin kullanımı için kolaylıklar sağlasa da kulaklık ile kullanılması durumu kişiyi dış ortamdan izole etmektedir. Zaten mevcut olan görme engelinin yanı sıra dış ortamda ki sesleri de duyamaması kişiye ayrı bir engel teşkil etmektedir.

Mobilitenin hayatımızda önemli yer kapladığı günümüz şartlarında bu tip çözümler hala engelli kişinin sabit bir durumda bulunmasını gerektirmektedir. Bu olumsuzluk düşünülerek farklı bir bakış açısıyla bu çalışmada geliştirilecek cihazla okunacak metin kişinin hareket kabiliyetini kısıtlamayacak niteliktedir. Her türlü bilgiye erişim ve iletimin kolay olduğu günümüz teknolojisi düşünülerek akıllı cihazlar yardımı ve kablosuz bir iletişim yöntemi ile engelli kişinin okuma yapması sağlanacaktır.

Her ne kadar Braille alfabesi ile görme engellilerin okuma ihtiyaçlarına bir çözüm bulunmuş olsa da bu çözümün verimli olabilmesi için çeşitli koşulların sağlanmış olması gerekmektedir. Bunlar arasında, okunacak metnin kabartma bir form üzerine işlenmiş olması, görme engelli kişinin bunları okuyabilmesi için formun düz bir zeminde kullanılması ve kişinin sabit bir durumda olması gerekmektedir. Ancak mobilitenin önemli bir yere sahip olduğu günümüz şartlarında Braille alfabesi tek başına yeterli değildir. Çünkü engelsiz bir kişi arabada, otobüste, trende rahatlıkla herhangi bir metin okuyabilirken Braille'nin getirdiği kabartma sistemi çözümü uygulama açısından bu gibi yerlerde okuma eyleminin başarısını olumsuz yönde oldukça fazla etkilemektedir.

Yukarıda sayılan nedenlerden dolayı, bu çalışmada görme engelli bireyin hem rahatlıkla okuma yapabilmesi hem de dış çevreden izole olmaması için Braille alfabesi sadece parmak ucundaki boğumları kullanması yerine vücudunun diğer bölümlerini de kullanabilmesi için titreşime karşı hassasiyeti araştırılmıştır. Bu çalışmanın diğer amaçları görme engelli bireyin dış görünümünde olumsuz bir görüntü oluşturmadan okuma yapması ve sayısal ortama aktarılan sınırsız bilgiye ulaşmada kolaylık sağlamasıdır. Bu amaçla vücudun çeşitli bölgelerinin titreşime karşı hassasiyeti geliştirilen modüllerle ölçülmüştür.

Çalışmanın geri kalanında; ikinci bölümde geliştirilen modüller hakkında bilgi ve yöntem verilmiştir. Sonraki bölümde bu yöntem ile yapılan ölçümlerin sonuçları yer almaktadır. Son bölümde de değerlendirme ve ileriki çalışmalar hakkında bilgi verilmiştir.

\section{Materyal ve Metot}

Hassasiyetin sorun olmaktan kalkması amacıyla, nokta büyüklüğündeki kabartma sistem yerine her bir nokta için bir titreşim modülü geliştirilmiştir. "Braille modülü” olarak adlandırdığımız bu modüller, titreşim vererek kişinin hissetmesini sağlayacak olan bir e-ISSN: $2148-2683$ 
adet titreşim motoru, bu motoru dış etkilere karşı korunmasını sağlayacak motoru çevreleyen modül yuvası ve modül yuvası içerisinde bulunan elemanlara enerji taşıyacak olan kablodan oluşmaktadır.

\subsection{Braille Modülü}

Braille alfabesi, görme engelli kişilerin okumasına yardımcı olmak için geliştirilmiş bir alfabedir. Braille modülleri, Braille alfabesini herhangi bir elektronik cihazdan sinyal alarak kişinin okuma yapması için titreşim olarak algılaması amacıyla ve harf sinyallerini vücut üzerinde elektronik olarak görüntülemek için geliştirilmiştir. Bu çalışmada bahsedilen Braille modülleri bünyesinde titreşim motoru, koruyucu kapsül, motor enerji kablosu için soket barındırmaktadır ve Şekil 1'de gösterilmiştir.

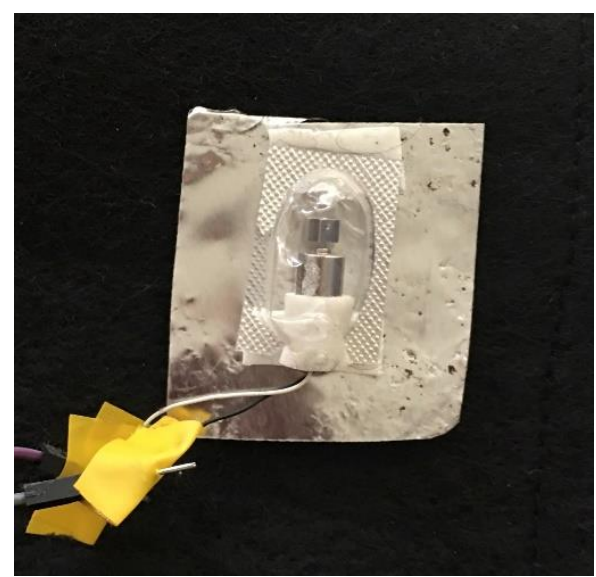

Şekil 1. Braille titreşim modülü

\subsection{Titreşim Motoru}

$6.7 \times 14.5 \mathrm{~mm}$ boyutlarındaki bu titreşim motoru çeşitli telefonların ve titreşim özelliğine sahip ürünlerin de içinde yer alan, mil üzerindeki serbest ağırlık sayesinde dönme esnasında titreşim hareketi yapmaktadır.

Motorlar, 1.7 ile 3.6V arası bir gerilimde çalışabilmektedir. 3V gerilimde yaklaşık 14000rpm dönme hızına ve 1.5g 'lik bir titreşim genliğine sahiptir.

Motor uçları kabloludur. Kablo uzunluğu 50mm'dir. Bu çalışmada Arduino karttan gelen sinyale göre kendi özelliklerinde çalışarak görme engelli kişiyi uyarmak amacıyla titremektedir. Şekil 2'de gösterildiği gibidir.

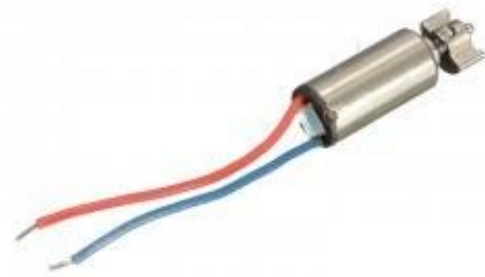

Şekil 2. Titreşim motoru

\subsection{Koruyucu Kapsül}

Koruyucu kapsüller, Braille modülleri içerisindeki titreşim motorlarını korumak amacıyla tasarlanmıştır. Koruyucu kapsülün alt kısmı titreşimi daha fazla hissedilir hale getirmek için metal bir parçadan üst kısmı ise titreşim motorunun rahatça hareket etmesini sağlamak amacı ile bombeli plastik bir parçanın titreşim motorları üzerine yerleştirilmesinden oluşur. Titreşim motorlarının koruyucu kapsüle yerleştirilmiş hali Şekil 1'de gösterilmiştir.

\subsection{Arduino Kart}


Şekil 1 de görülen titreşim modülünden altı adet hazırlanmıştır. Braille titreşim motorunu istenilen düzende çalıştırılması amacıyla bir Arduino kart kullanılmıştır. Bu kart ile bilgisayardan gönderilen harf sinyali titreşim motorlarına gerekli yazılım ile iletilerek istenilen titreşim elde edilmektedir. Arduino 'nun temel kartı olan arduino uno modeli kullanılmıştır. ATMega328 mikrodenetleyicisi bulunur. 14 Dijital G/Ç Pini, 6 PWM Çıkışı, 6 ADC Girişi vardır. 32 KB Flash hafızaya sahiptir. Şekil 3'de gösterildiği gibidir.

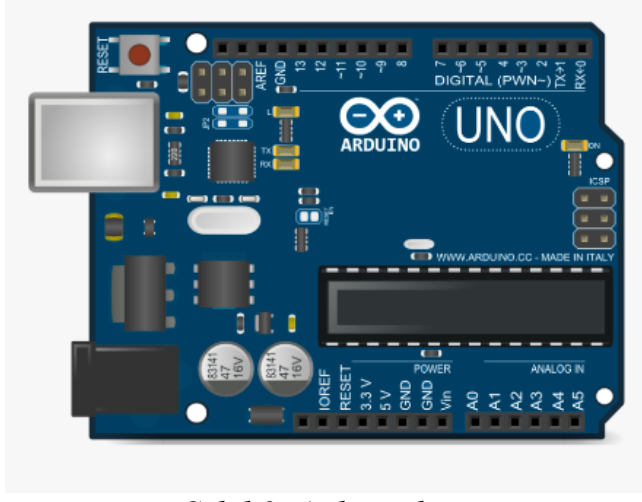

Şekil 3. Arduino kart

Braille modülleri Arduino kart üzerinde bulunan girişlere uygulanan yazılımda ki sıraya göre dizilmişlerdir. Gerekli titreşim motoru gerekli Arduino kart girişine adapte edilerek istenilen braille düzeni oluşturulur. Alfabede bulunan bütün harfler ve sayılar dahil olmak üzere braille harf düzenindeki bütün kombinasyonları oluşturabilecek nitelikte geliştirilmiştir. Braille modüllerinin sinyal girişleri ve besleme yapılacak girişlerinin Arduino üzerinde yerleşimi Şekil 4'de görüldüğü gibidir.

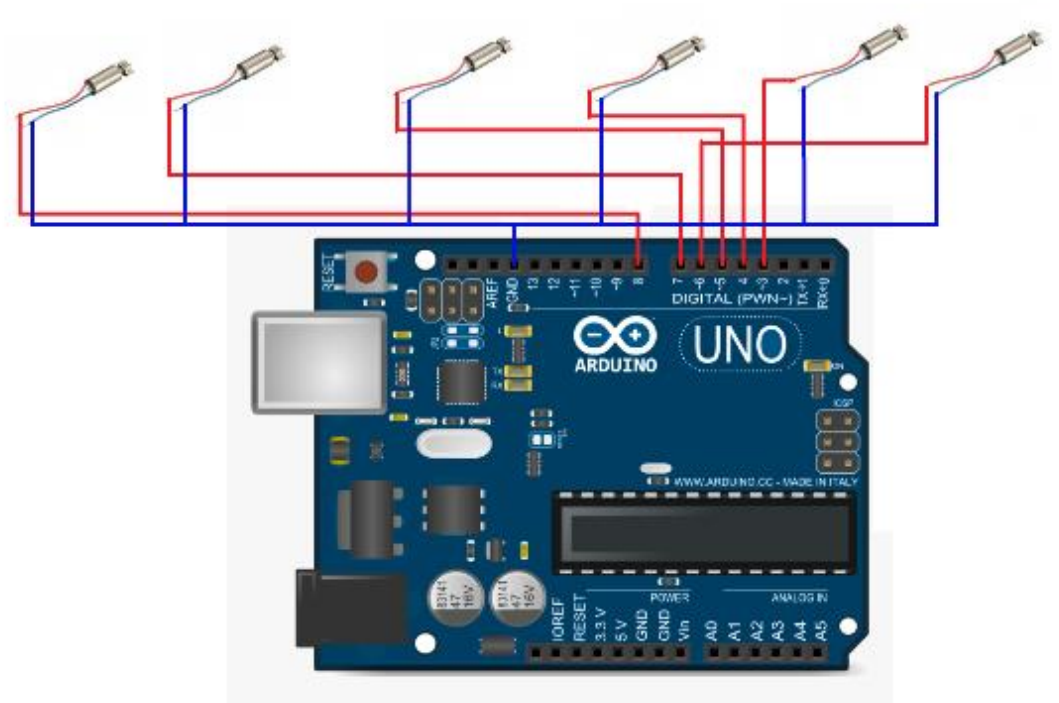

Şekil 4. Arduino kart ile titreşim motorlarının bağlantısı

Şekil 4'de görüldüğü üzere kırmızı ile ifade edilen çizgiler Arduino'dan titreşim motoruna biginin iletimini sağlayacak girişler olup herbir titreşim motoru için tekrar eder. Mavi ile ifade edilen çizgiler ise titreşim motorlarının topraklaması için kullanılmıştır.

\section{Araştırma Sonuçları ve Tartışma}

Braille alfabesi tekniği, 6 adet kabartma noktanın insan parmağının bir boğumunun içi gibi küçük bir alanda faklı kombinasyonlar ile harflerin temsiline dayanmaktadır. Bu yönüyle, parmak yüzeyindeki hissiyatın hassasiyetindeki değişim kişinin okumasını olumsuz etkilemektedir. Bu yüzden harflerin temsili vücut üzerinde daha büyük bir alana yayılmalıdır. Bununla beraber, noktasal büyüklükteki kabartmaları anlamak için, kişi bütün dikkatini buna vermekte ve bu yüzden de sabit bir şekilde durup kabartma noktaları hissetmeye çalı̧̧maktadır.

$\mathrm{Bu}$ çalışmada, Braille harf tekniğinin uygulama alanı vücut üzerinde kolların, göğüs ve sırt bölgesinin hassasiyeti araştırılmıştır. Hassasiyetin sorun olmaktan kalkması amacıyla, nokta büyüklüğündeki kabartma sistem yerine her bir nokta için geliştirilen Braille titreşim modülü kullanılmıştır. Şekil 5’te Braille modüllerinin kollar üzerindeki düzeni görülmektedir. Şekil 6'da ise göğüs ve sırt bölgelerine yapılan yerleşim gösterilmiştir. 




Şekil 5. Kollar üzerinde Braille modülleri
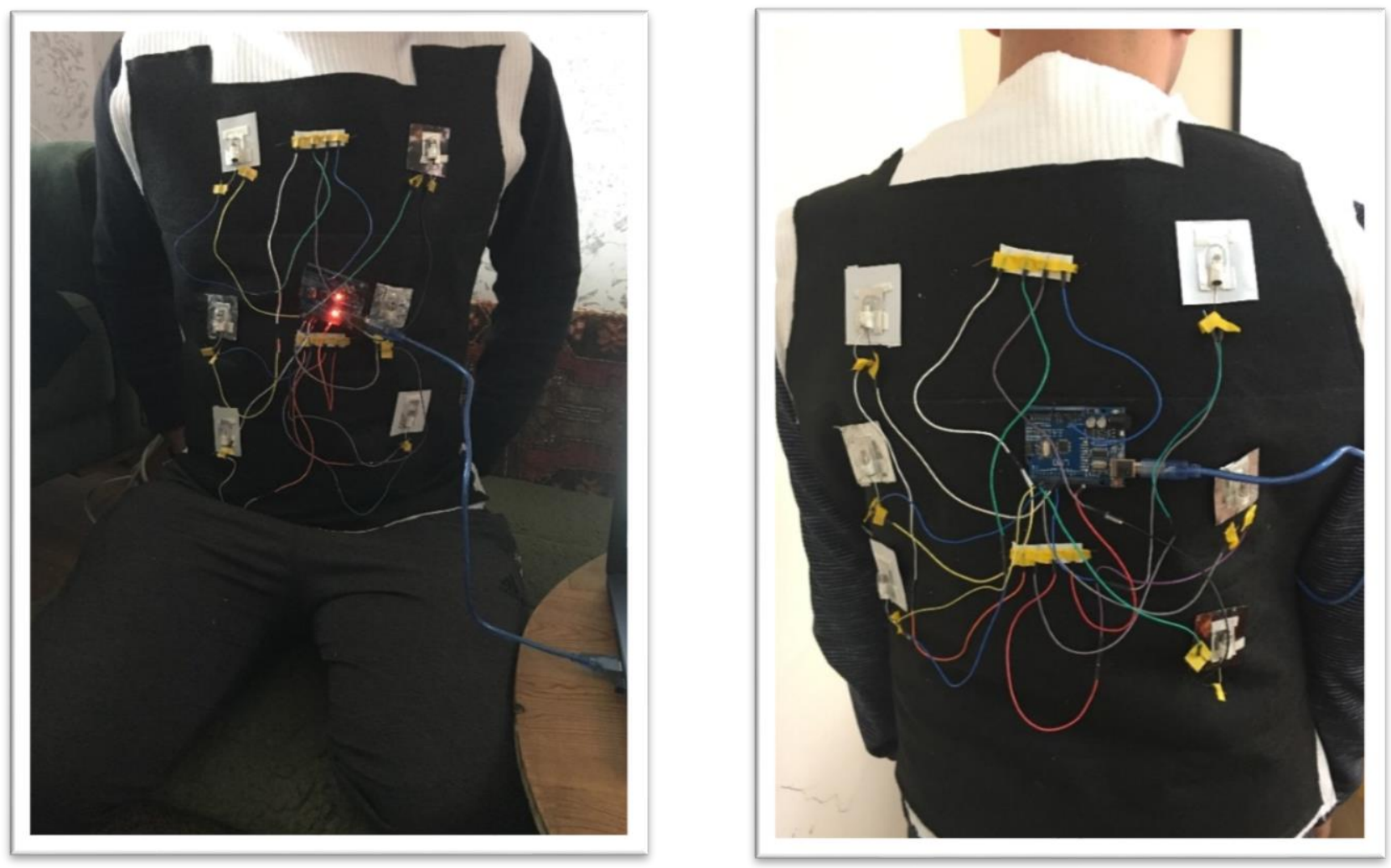

Şekil 6. Vücudun göğ̈̈s bölgesinde (solda) ve sirt bölgesinde (sağda) Braille modülleri.

Vücut bölgelerinin hassasiyetinin ölçümünde, Braille alfabesinde birbirinden farklı düzene sahip harflerden " $A$ ", "B”, "J" ve "K" harfleri seçilmiştir. Deneysel çalıșma için yaşları 25 ve 32 olan biri kadın diğeri erkek ve hiçbir engeli bulunmayan bireyler seçilmiştir. Deneysel çalışmaya katılan bireylerin kol, gögüs ve sırt bölgelerine Braillle modülleri yerleştirilmiş ve seçilen hafler için ilgili modüllerin tireşimi sağlanmıştır. Katılımcıların verdikleri yanıtlar doğrultusunda hafleri doğru bilme oranları tespit edilmiş ve Tablo 1'de verilmiştir.

Tablo 1 incelendiğinde, kollarda ve sırt bölgesinde yapılan testlerdeki başarı oranının daha düşük olduğu görülmektedir. Bunun nedeni olarak kollarda modüllerin birbirine çok yakın olması ve dolayısıyla hissiyatta doğruluğun az olması gösterilebilir. Bir diğer 
neden olarak da kol ve sırt bölgesinin doku itibariyle kaslı olması söylenebilir. Bunların yanında, göğüs bölgesinde daha fazla doğruluk oranı elde edilmesinin sebebi olarak hem yoğunluk olarak az miktarda kas dokusuna sahip olması hem de modüllerin yerleşimi olarak daha fazla alanın olması gösterilebilir.

Tablo 1. Deneysel çalışma sonuçları

\begin{tabular}{|c|c|c|c|c|}
\hline Vücut Bölgesi & \multicolumn{3}{|c|}{ Harfler } & Hissetme \\
\hline Sirt & \multirow{3}{*}{ 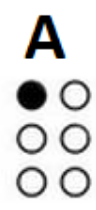 } & \multirow{3}{*}{\multicolumn{2}{|c|}{ 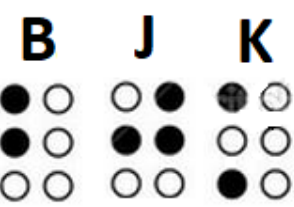 }} & $\% 25$ \\
\hline Göğüs & & & & $\% 75$ \\
\hline Kollar & & & & $\% 25$ \\
\hline
\end{tabular}

\section{Sonuç}

$\mathrm{Bu}$ çalı̧̧manın temel amacı görme engelli bireylerin hareket alanını daraltmadan teknoloji ile uyumlu bir okuma sistemi için vücudun titreşime hassasiyetinin ölçülmesidir. Bu amaç için hazırlanan modüller ile vücudun üç farklı bölgesine harfleri temsil eden Braille düzeninde titreşim verilmiş ve kişinin bunları doğru tespit etmedeki başarısı ölçülmüştür. Gerek seçilen vücut bölgeleri gerekse geliştirilen modüller ileriki çalışmalar için bir zemin niteliğinde olup görme engellilerin ihtiyaçları doğrultusunda tasarlanmış Braille alfabesi ile okuma yapabileceği, ulaşılması ve taşınması kolay, ucuz ve fiziksel görüntüsünde olumsuzluğa sebep olmayan bir cihaz geliştirilmesine yöneliktir.

Böylece engelli bireyin mobilitesini kısıtlamadan kişisel gelişimine katkıda bulunabilmek, görme engelli kişilerin okuma konusundaki sorunlarına çözüm üretebilmek, ilgili alfabenin teknolojiye adapte olmasıyla, akıllı cihazlarla birlikte kullanılması gibi, dijital ortamdaki verilere kolayca erişebilmesi ve bu sayede kişiyi sosyal ortamdan uzaklaştırmadan sorunlarının çözümüne katkı sağlanacaktır. Bundan sonra, geliştirilen düzeneğin akıllı cihazlar ile kablosuz haberleşmesi üzerinde çalışılıp görme engelli bireyleri sayısal ortamdaki metinlere ulaşması için alternatif bir çözüm üretilecektir. Hedeflenen sistem için patent başvurusu yapılmıştır [16].

\section{Kaynakça}

[1] Elmannai, W., \& Elleithy, K. (2017). Sensor-based assistive devices for visually-impaired people: Current status, challenges, and future directions. Sensors, 17(3), 565.

[2] Ahmad, F., Ishaq, I., Ali, D., \& Riaz, M. F. (2016, December). Bionic Kinect device to assist visually impaired people by haptic and voice feedback. In 2016 International Conference on Bio-engineering for Smart Technologies (BioSMART) (pp. 1-4). IEEE.

[3] Joseph, S. L., Xiao, J., Zhang, X., Chawda, B., Narang, K., Rajput, N., ... \& Subramaniam, L. V. (2015). Being aware of the world: Toward using social media to support the blind with navigation. IEEE transactions on human-machine systems, 45(3), $399-405$.

[4] Xiao, J., Joseph, S. L., Zhang, X., Li, B., Li, X., \& Zhang, J. (2015). An assistive navigation framework for the visually impaired. IEEE Transactions on Human-Machine Systems, 45(5), 635-640.

[5] Andò, B., Baglio, S., Marletta, V., \& Valastro, A. (2015). A haptic solution to assist visually impaired in mobility tasks. IEEE Transactions on Human-Machine Systems, 45(5), 641-646.

[6] Kumar, K., Champaty, B., Uvanesh, K., Chachan, R., Pal, K., \& Anis, A. (2014, July). Development of an ultrasonic cane as a navigation aid for the blind people. In 2014 International Conference on Control, Instrumentation, Communication and Computational Technologies (ICCICCT) (pp. 475-479). IEEE.

[7] Battaglia, F., \& Iannizzotto, G. (2012). An open architecture to develop a handheld device for helping visually impaired people. IEEE Transactions on Consumer Electronics, 58(3), 1086-1093.

[8] El-Koka, A., Hwang, G. H., \& Kang, D. K. (2012, February). Advanced electronics based smart mobility aid for the visually impaired society. In 2012 14th International Conference on Advanced Communication Technology (ICACT) (pp. 257-261). IEEE.

[9] Galeotti, J., Horvath, S., Klatzky, R., Nichol, B., Siegel, M., \& Stetten, G. (2008). FingerSight ${ }^{\text {TM}: ~ f i n g e r t i p ~ c o n t r o l ~ a n d ~ h a p t i c ~}$ sensing of the visual environment. In ACM SIGGRAPH 2008 new tech demos (pp. 1-1).

[10] Horvath, S., Galeotti, J., Wu, B., Klatzky, R., Siegel, M., \& Stetten, G. (2014). FingerSight: Fingertip haptic sensing of the visual environment. IEEE Journal of Translational Engineering in Health and Medicine, 2, 1-9.

[11] Hirose, M., \& Amemiya, T. (2003, June). Wearable finger-braille interface for navigation of deaf-blind in ubiquitous barrier-free space. In Proceedings of the HCI International (Vol. 4, pp. 1417-1421).

[12] Sarkar, R., Das, S., \& Rudrapal, D. (2013, February). A low cost microelectromechanical Braille for blind people to communicate with blind or deaf blind people through SMS subsystem. In 2013 3rd IEEE International Advance Computing Conference (IACC) (pp. 1529-1532). IEEE.

[13] Eldem, A., \& Başçiftçi, F. (2015). Electronic and Computer-Assisted Refreshable Braille Display Developed for Visually Impaired Individuals. International Journal of Medical, Health, Pharmaceutical and Biomedical Engineering, 9(1).

[14] Russomanno, A., O’Modhrain, S., Gillespie, R. B., \& Rodger, M. W. (2015). Refreshing refreshable braille displays. IEEE transactions on haptics, 8(3), 287-297. 
[15] Culbertson, H., Schorr, S. B., \& Okamura, A. M. (2018). Haptics: The present and future of artificial touch sensation. Annual Review of Control, Robotics, and Autonomous Systems, 1, 385-409.

[16] Avşar, İ. and Furat, M. “Görme Engelli Alfabesi Okuma Sistemi,” TPE Başvuru no:2019/09429. 